\title{
Protective efficiency of oil compositions with Cortec VpCI-368D
}

\author{
L.G. Knyazeva, ${ }^{1}$ L.E. Tsygankova, ${ }^{1,2} \oplus *$ A.V. Dorokhov ${ }^{1}$ \\ and N.A. Kur' yato ${ }^{1,3}$
}

${ }^{1}$ All-Russian Scientific Research Institute of Use of Machinery and Oil Products, NovoRubezhnyi per., 28, 392022 Tambov, Russian Federation

${ }^{2}$ Derzhavin State University, ul. Internatsyonalnaya, 33, 392000 Tambov, Russian Federation

${ }^{3}$ Tambov State Technical University, ul. Sovetskaya, 106, 392000 Tambov, Russian Federation

*E-mail: vits21@mail.ru

\begin{abstract}
The protection of metals by coatings based on compositions of a number of petroleum oils with Cortec VpCI-368D has been studied by gravimetric and electrochemical methods. Cortec VpCI$368 \mathrm{D}$ is a blend of organic solvent with volatile inhibitor. Oil compositions with Cortec VpCI$368 \mathrm{D}$ are well wetted with water (contact angles less than $90^{\circ}$ ), they themselves spread over the steel surface (contact angles $1-3^{\circ}$ ), displacing water layers, and are characterized by low surface tension. The work of adhesion of the compositions studied was calculated. Wetting the coatings with water promotes the penetration of an aqueous medium through the pores in them to the metal surface and the formation of an ionic double electric layer there, as a result of which it becomes possible to carry out electrochemical measurements. The protective efficiency of the composition of industrial oil I-20A and Cortec VpCI-368D (5-10 wt\%) was estimated on the basis of polarization curves at a short-term exposure of a steel electrode with coating in a $0.5 \mathrm{M}$ $\mathrm{NaCl}$ solution $(Z=97-98 \%)$. Compositions of petroleum oils with Cortec VpCI-368D (5$10 \mathrm{wt} \%$ ) showed the high protective efficiency in relation to carbon steel in a thermal moisture chamber (97-100\%) and natural conditions (80-94\%). These compositions are most effective in relation to brass L-62 $(Z=70-80 \%)$ in a chloride-containing neutral solution at an exposure of $456 \mathrm{~h}$; their use for protecting copper is impractical, since the protective effect does not exceed $40 \%$. Only compositions with commercial oil I-20A $(Z=67 \%)$ are reasonable in these conditions in relation to carbon steel. Consumption of Cortec VCl-368D for coating deposition at 20 and $70^{\circ} \mathrm{C}$ was calculated.
\end{abstract}

Keywords: oil compositions, protective effectiveness, atmospheric corrosion, chloride solution, field tests, thermal moisture chamber.

Received: February 24, 2021. Published: April 6, 2021

doi: $\underline{10.17675 / 2305-6894-2021-10-2-4}$

\section{Introduction}

Various oil compositions [1-5] are widely used for temporary anticorrosive protection of equipment against atmospheric corrosion. Interest in application of volatile corrosion 
inhibitors for these purposes, the use of which is limited by the need to create closed spaces [6-9], has also grown in recent years. The combination of contact corrosion inhibitors with volatile components is undoubtedly relevant and modern if it will slow down corrosion processes, especially in places of defects on the metal surface, and enhance the protective properties of the compositions.

Cortec Corporation, USA (on the territory of Russia and the CIS countries, the official representative is the company LLC "CORTEC RUS") offers a composition of an organic solvent with a volatile inhibitor (30\%) Cortec VpCI-368D for temporary protection against atmospheric corrosion. Long-term (up to 5 years) protection of ferrous and non-ferrous metals against corrosion under the open sky is predicted. The composition forms a translucent, waxy, self-tightening film that can be removed with common solvents or an alkaline cleaner.

The purpose of this work is to study a protection of carbon steel, copper and brass against atmospheric corrosion by means of petroleum oil compositions with Cortec VpCI$368 \mathrm{D}$.

\section{Experimental technique}

Industrial (I-20A), transformer (TKp), commercial motor (M10G2k) and waste motor (WMO) oils were used as a solvent-support in oil compositions.

The concentration of Cortec VpCI-368D in the oil compositions was 3-10 wt\%.

The studies were carried out on samples of carbon steel St 3 with a composition, wt $\%$ : C 0.20; Mn 0.51; Si 0.15; P 0.04; S 0.05; Cr 0.32; Ni 0.21; Cu 0.23; Fe 98.29; copper $\mathrm{M} 2: \mathrm{Al} \leq 0.002 ; \mathrm{Zn} \leq 0.005 ; \mathrm{Mn} \leq 0.01 ; \mathrm{Cr} \leq 0.05 ; \mathrm{Si} \leq 0.01 ; \mathrm{Zr} \leq 0.05 ; \mathrm{Cu}$ 99.7; two-phase $(\alpha+\beta)$ brass L62: $\mathrm{Zn} 22.5 ; \mathrm{Mn} 2.9 ; \mathrm{Fe} 2.0 ; \mathrm{Al} 4.1 ; \mathrm{Cu}$ is the rest.

The oil composition coatings were deposited by immersion of the samples into the bath containing the composition at $20^{\circ} \mathrm{C}$ for 10 seconds. After that, the samples were kept in a suspended state at room temperature to drain the excess oil composition and to form a protective film. The thickness of the formed film $(\mu \mathrm{m})$ was evaluated gravimetrically, assuming the layer to be uniform, according to the formula:

$$
h=\frac{\Delta m \cdot 10^{6}}{S \cdot \rho}
$$

where $\Delta m$ is the change in the mass of the sample due to the formation of the coating, $\mathrm{kg} ; S$ is the surface area, $\mathrm{m}^{2} ; \rho$ is the density of the preservation material, $\mathrm{kg} / \mathrm{m}^{3}$.

Corrosion tests were carried out in a $0.5 \mathrm{M} \mathrm{NaCl}$ solution (GOST 9.042-75), a thermal moisture chamber G-4 (GOST 9.054-75), and in natural conditions. The corrosion rate was calculated from the weight loss of the samples and by extrapolating the Tafel sections of the polarization curves to the corrosion potential.

The recalculation of the corrosion rate from electrical units to mass units was carried out according to the formula: 


$$
K=\gamma i_{\text {cor }},
$$

where $K$ is the corrosion rate, $\mathrm{g} /\left(\mathrm{m}^{2} \cdot \mathrm{h}\right), i_{\text {cor }}$ is the corrosion current, $\mathrm{A} / \mathrm{m}^{2} ; \gamma$ is the electrochemical equivalent of iron, taking into account its transition to solution (oxidation) in the form of $\mathrm{Fe}^{2+}(\mathrm{g} / \mathrm{A} \cdot \mathrm{h})$.

The protective effectiveness of the compositions was evaluated by the formula:

$$
Z=\frac{K_{0}-K}{K_{0}} \cdot 100 \%,
$$

where $K_{0}$ and $K$ are metal corrosion rates in the absence and presence of a film of the oil composition, respectively.

Potentiodynamic polarization measurements at a potential sweep rate of $0.66 \mathrm{mV} / \mathrm{s}$ were carried out in $0.5 \mathrm{M} \mathrm{NaCl}$ solution in an electrochemical cell made of Pyrex glass with anodic and cathodic spaces separated by a thin section using an IPC-Pro MF potentiostat. The reference electrode was a saturated aqueous silver/silver chloride, the auxiliary electrode was smooth platinum. The working electrode was reinforced with a mandrel made of ED-5 epoxy resin hardened with polyethylene polyamine. Potentials were recalculated according to normal hydrogen electrode.

The contact angles of wetting $(\theta)$ of the oil compositions were determined using the EASYDROP device and by the calculation method [10]. The values of surface tension $(\sigma)$ were obtained by the method of ring tearing on a Du-Nui device, and the value of the work of adhesion $\left(W_{\mathrm{a}}\right)$ was calculated according to the formula:

$$
W_{\mathrm{a}}=\sigma(1+\cos \theta)
$$

\section{Results and Discussion}

The quality of wetting and spreading of the compositions over the metal surface affects the appearance, continuity, adhesive strength and protective ability of coatings.

The values of the contact angles $\left(\theta_{1}\right)$ of wetting of the oil compositions under study with water, obtained using the EASYDROP device, do not exceed $90^{\circ}$ (Table 1), therefore, water actively wets the investigated coatings. The rapid spreading of the oil compositions drops themselves over the $\mathrm{St} 3$ steel surface did not allow determining their contact angles $\left(\theta_{2}\right)$ using the EASYDROP device; therefore, a calculation method was used [10].

The maximum contact angles $\left(\theta_{1}\right.$ and $\left.\theta_{2}\right)$ were obtained for compositions based on WMO, however, the difference in values for compositions based on other oils is insignificant (Table 1). The $\theta_{2}$ values of the compositions are much lower than the corresponding values for distilled water $\left(77^{\circ}\right)$; therefore, all the studied oil compositions should effectively displace the surface phase water layers.

The values of surface tension $(\sigma)$ and work of adhesion $\left(W_{\mathrm{a}}\right)$ of different oil compositions are close to each other and tend to decrease slightly with increasing concentration of Cortec VpCI-368D (Table 1). 
Table 1. Contact angles of wetting of the Cortec VpCI-368 D oil compositions with water $\left(\theta_{1}\right)$ and steel with oil compositions $\left(\theta_{2}\right)$, surface tension and work of adhesion of the compositions.

\begin{tabular}{|c|c|c|c|c|c|}
\hline Oil & $\begin{array}{c}\text { Cortec VpCI-368 D } \\
\text { concentration, wt \% }\end{array}$ & $\theta_{1}$, deg. & $\theta_{2}$, deg. & $\begin{array}{c}\sigma(\mathbf{l} / \mathbf{g}) \\
(\mathbf{m N} / \mathbf{m})\end{array}$ & $\begin{array}{c}W_{\mathrm{a}}, \\
(\mathbf{m N} / \mathbf{m})\end{array}$ \\
\hline \multirow[t]{4}{*}{$\mathrm{TKp}$} & 3 & 61 & 0.95 & 20.79 & 41.51 \\
\hline & 5 & 62 & 0.72 & 20.04 & 40.08 \\
\hline & 7 & 56 & 0.70 & 20.35 & 40.70 \\
\hline & 10 & 56 & 0.70 & 20.35 & 40.70 \\
\hline \multirow[t]{4}{*}{$\mathrm{I}-20 \mathrm{~A}$} & 3 & 54 & 1.35 & 17.33 & 34.66 \\
\hline & 5 & 56 & 1.36 & 17.23 & 34.46 \\
\hline & 7 & 52 & 1.10 & 16.55 & 33.10 \\
\hline & 10 & 49 & 1.11 & 16.66 & 33.32 \\
\hline \multirow[t]{4}{*}{ M10G2k } & 3 & 73 & 1.12 & 19.63 & 39.26 \\
\hline & 5 & 63 & 1.18 & 19.90 & 39.72 \\
\hline & 7 & 76 & 1.28 & 18.94 & 37.86 \\
\hline & 10 & 70 & 1.27 & 18.89 & 37.76 \\
\hline \multirow[t]{4}{*}{ WMO } & 3 & 79 & 3.10 & 25.79 & 51.58 \\
\hline & 5 & 78 & 3.00 & 20.04 & 40.08 \\
\hline & 7 & 72 & 2.84 & 18.85 & 37.70 \\
\hline & 10 & 70 & 1.76 & 18.73 & 37.46 \\
\hline
\end{tabular}

Although the oil compositions are capable to displace the phase water layers on the metal surface, nevertheless, the wetting of the oil coatings with water promotes the penetration of the aqueous medium through the pores in them to the metal surface and the formation of an ionic double electric layer there, as a result of which it becomes possible to carry out electrochemical measurements $[3,4]$. The protective efficacy of oil formulations is due to the adsorption of inhibitors contained in them on the metal surface.

Electrochemical studies make it possible to give an express assessment of the protective properties of the studied oil compositions. The polarization curves of a steel electrode coated with the compositions based on I-20A oil measured after a 15 -minute exposure in a $0.5 \mathrm{M}$ $\mathrm{NaCl}$ solution are shown in Figure 1. 


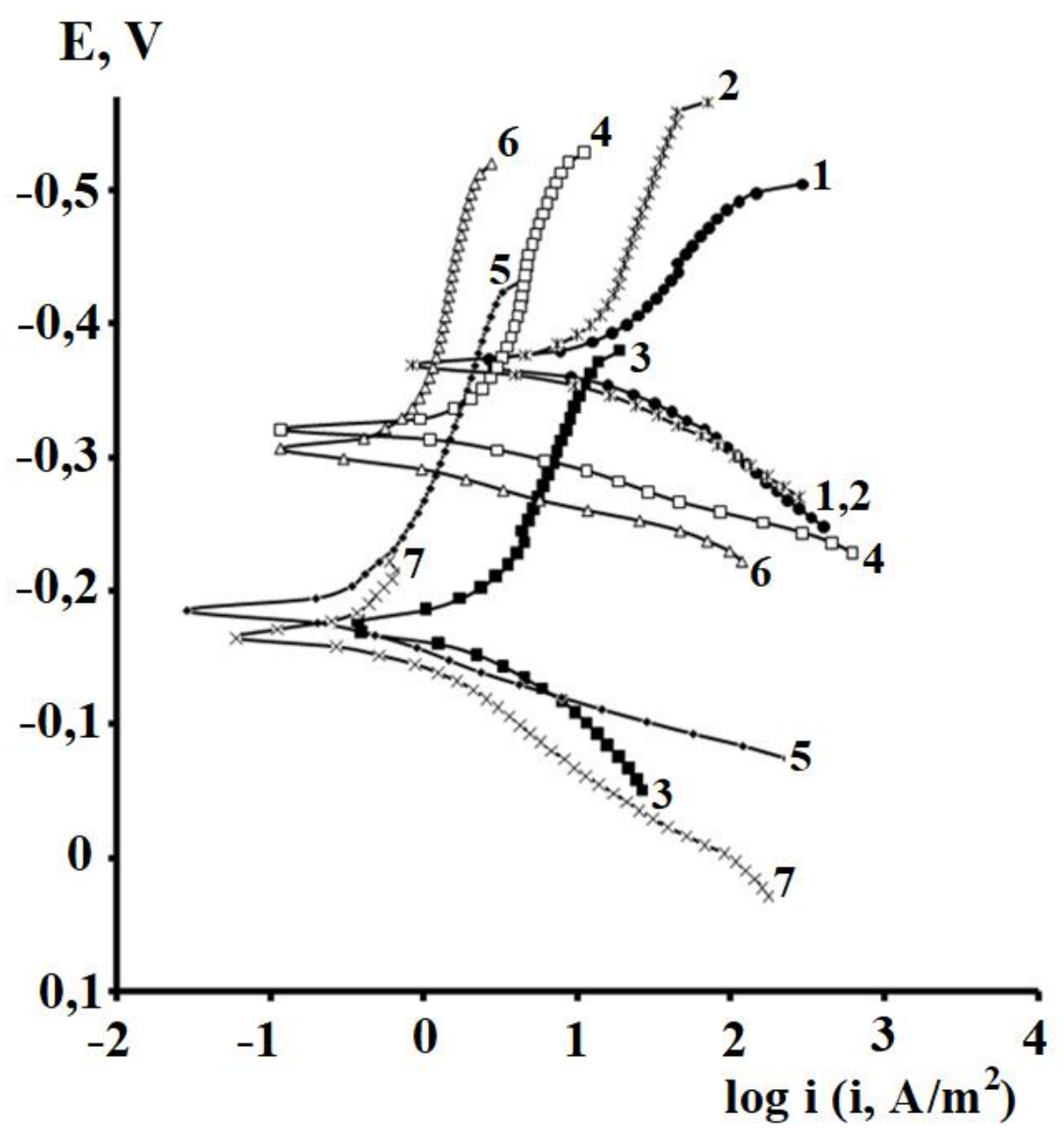

Figure 1. Polarization curves of St3 steel coated with protective compositions in $0.5 \mathrm{M} \mathrm{NaCl}$ solution: 1 - no coating, 2 - I-20A; (3-7) I-20A with Cortec VpCI-368 D, mass. \%: 3 - 100; $4-3 ; 5-5 ; 6-7 ; 7-10$.

The corrosion potential ( $E_{\text {cor }}$ ) of a steel electrode in the absence of a coating is $-0.37 \mathrm{~V}$, the corrosion current density $\left(i_{\text {cor }}\right)$ is $5.01 \mathrm{~A} / \mathrm{m}^{2}$. The slope of the Tafel section of the anodic polarization curve is close to $56 \mathrm{mV}$ (Table 2), which corresponds to the value of $2.3 R T / F$ typical of anodic ionization of iron in chloride media in the absence of passivation. $E_{\text {cor }}$ retains the same value after applying a film of fresh I-20A oil, and $i_{\text {cor }}$ decreases to $2.14 \mathrm{~A} / \mathrm{m}^{2}$. The anodic curves practically coincide in both cases, and the cathodic process on the electrode with the I-20A film is inhibited. The protective efficiency of such a coating $(Z)$ is $57 \%$. The oil composition with Cortec VpCI-368D significantly reduces corrosion currents and, accordingly, increases the protective effectiveness of the coating (Figure 1, Table 2). At the same time, a slowdown of the anodic process is observed, especially significant in the presence of $5-10 \%$ additive. A quick transition to the limiting oxygen current is observed on the cathodic curves. 
Table 2. Protective properties of the compositions based on I-20A and Cortec VCl-368D applied to St3 steel.

\begin{tabular}{cccccc}
\hline Coating composition & $-\boldsymbol{E}_{\mathbf{c o r}}, \mathbf{V}$ & $\boldsymbol{I}_{\mathbf{c o r}}, \mathbf{A} / \mathbf{m}^{\mathbf{2}}$ & $\boldsymbol{b}_{\mathbf{c}}, \mathbf{V}$ & $\boldsymbol{b}_{\mathbf{a}}, \mathbf{V}$ & $\boldsymbol{Z}, \boldsymbol{\%}$ \\
\hline Absent & 0.37 & 5.01 & 0.102 & 0.056 & - \\
I-20A & 0.37 & 2.10 & 0.155 & 0.065 & 57 \\
VCl-368D & 0.17 & 0.63 & 0.090 & 0.043 & 87 \\
3\% VCl-368D in I-20A & 0.32 & 0.54 & 0.272 & 0.034 & 89 \\
5\% VCl-368D in I-20A & 0.18 & 0.13 & 0.195 & 0.034 & 98 \\
7\% VCl-368D in I-20A & 0.30 & 0.10 & 0.384 & 0.026 & 98 \\
10\% VCI-368D in I-20A & 0.16 & 0.17 & 0.160 & 0.035 & 97 \\
\hline
\end{tabular}

Coating with a $3 \mathrm{wt} \%$ Cortec VCl-368D composition exhibits almost the same protective effect as a coating with an individual Cortec $\mathrm{VCl}-368 \mathrm{D}$. The protective effectiveness of compositions with 5-10\% additive to I-20A reaches $97-98 \%$.

Protective compositions based on all studied oils containing 5-10 mass. \% Cortec VCl$368 \mathrm{D}$ are characterized by a $Z$ value of the order of $97-100 \%$ during accelerated ( 960 hours) corrosion tests in a thermal moisture chamber G-4 (Table 3). The lowest $Z$ values (97-98\%) are typical for compositions based on I-20A oil. Obviously, this is due to the lowest value of the work of adhesion of these compositions in comparison with the rest.

Table 3. Results of corrosion tests of steel samples with oil coatings in a thermal moisture chamber G-4 at an exposure of 960 hours.

\begin{tabular}{ccccc}
\hline \multirow{2}{*}{ Oil } & $\begin{array}{c}\text { Cortec VpCI-368 D } \\
\text { concentration, wt } \%\end{array}$ & $\begin{array}{c}\text { Coating thickness, } \\
\boldsymbol{\mu m}\end{array}$ & $\begin{array}{c}\boldsymbol{K}, \\
\mathbf{g} /\left(\mathbf{m}^{\mathbf{2}} \mathbf{h}\right)\end{array}$ & $\boldsymbol{Z}, \boldsymbol{\%}$ \\
\hline \multirow{3}{*}{ TKp } & Control & 0 & 0.1225 & - \\
& 0 & 11 & 0.1086 & 20 \\
& 3 & 13 & 0.0085 & 93 \\
& 5 & 13 & 0.0002 & 99 \\
& 10 & 14 & 0.0002 & 99 \\
\hline \multirow{3}{*}{ I-20A } & Control & 0 & 0.1225 & - \\
& 0 & 13 & 0.0448 & 63 \\
& 3 & 14 & 0.0106 & 91 \\
& 5 & 14 & 0.0023 & 98 \\
& 7 & 15 & 0.0023 & 98 \\
& 10 & 15 & 0.0015 & 99 \\
\hline
\end{tabular}




\begin{tabular}{ccccc}
\hline \multirow{2}{*}{ Oil } & $\begin{array}{c}\text { Cortec VpCI-368 D } \\
\text { concentration, wt } \%\end{array}$ & $\begin{array}{c}\text { Coating thickness, } \\
\boldsymbol{\mu m}\end{array}$ & $\begin{array}{c}\boldsymbol{K}, \\
\mathbf{g} /\left(\mathbf{m}^{2} \mathbf{h}\right)\end{array}$ & $\boldsymbol{Z}, \boldsymbol{\%}$ \\
\hline \multirow{3}{*}{ M10G2k } & Control & 0 & 0.1225 & - \\
& 0 & 15 & 0.0502 & 59 \\
& 3 & 15 & 0.0072 & 94 \\
& 5 & 16 & 0.0002 & 99 \\
& 10 & 17 & 0.0001 & $\sim 100$ \\
\hline \multirow{3}{*}{ WMO } & Control & 0 & 0.1225 & - \\
& 0 & 17 & 0.0282 & 77 \\
& 3 & 18 & 0.0024 & 98 \\
& 5 & 19 & 0.0001 & $\sim 100$ \\
& 10 & 21 & 0.0001 & $\sim 100$ \\
\hline
\end{tabular}

Gravimetric corrosion tests of steel samples covered by the oil compositions were also carried out in a $0.5 \mathrm{M} \mathrm{NaCl}$ solution with a duration of 456 hours (Table 4). The protective efficiency of the oil compositions with such a long exposure in a chloride solution turned out to be noticeably lower than in a thermal moisture chamber and in a chloride solution with short-term exposure (according to the polarization curves). The reason, obviously, is in the aggressive action of $\mathrm{Cl}^{-}$- ions, which are absent during tests in a thermal moisture chamber and did not fully manifest themselves when the samples were kept in the solution for a short time. Compositions of I-20A oil with a concentration of additive equal to 5-10\% are more effective than compositions based on other oils.

Table 4. Results of gravimetric corrosion tests in a $0.5 \mathrm{M} \mathrm{NaCl}$ solution at an exposure of 456 hours.

\begin{tabular}{|c|c|c|c|c|c|c|c|}
\hline \multirow[b]{2}{*}{ Oil } & \multirow{2}{*}{$\begin{array}{c}\text { Cortec VpCI- } \\
368 \mathrm{D} \\
\text { concentration, } \\
\text { wt } \%\end{array}$} & \multicolumn{2}{|c|}{ Steel St3 } & \multicolumn{2}{|c|}{ Copper M2 } & \multicolumn{2}{|c|}{ Brass L62 } \\
\hline & & $\begin{array}{l}K \cdot 10^{-3} \\
\mathbf{g} /\left(\mathbf{m}^{2} \mathbf{h}\right)\end{array}$ & $\begin{array}{l}Z, \\
\%\end{array}$ & $\begin{array}{l}K \cdot 10^{-3} \\
g /\left(\mathbf{m}^{2} \mathbf{h}\right)\end{array}$ & $\begin{array}{l}Z, \\
\%\end{array}$ & $\begin{array}{l}K \cdot 10^{-3} \\
g /\left(\mathbf{m}^{2} \mathbf{h}\right)\end{array}$ & $\begin{array}{l}Z, \\
\%\end{array}$ \\
\hline & Control & 122.9 & - & 30.0 & - & 30.0 & - \\
\hline \multirow{5}{*}{$\mathrm{I}-20 \mathrm{~A}$} & 0 & 98.0 & 20 & 20.0 & 33 & 26.4 & 12 \\
\hline & 3 & 86.0 & 30 & 20.0 & 33 & 6.0 & 80 \\
\hline & 5 & 40.6 & 67 & 18.0 & 40 & 9.0 & 70 \\
\hline & 7 & 40.6 & 67 & 18.0 & 40 & 9.0 & 70 \\
\hline & 10 & 40.6 & 67 & 18.0 & 40 & 14.1 & 53 \\
\hline
\end{tabular}




\begin{tabular}{|c|c|c|c|c|c|c|c|}
\hline \multirow[b]{2}{*}{ Oil } & \multirow{2}{*}{$\begin{array}{c}\text { Cortec VpCI- } \\
368 \mathrm{D} \\
\text { concentration, } \\
\text { wt } \%\end{array}$} & \multicolumn{2}{|c|}{ Steel St3 } & \multicolumn{2}{|c|}{ Copper M2 } & \multicolumn{2}{|c|}{ Brass L62 } \\
\hline & & $\begin{array}{l}K \cdot 10^{-3}, \\
\mathbf{g} /\left(\mathbf{m}^{2} \mathbf{h}\right)\end{array}$ & $\begin{array}{l}Z, \\
\%\end{array}$ & $\begin{array}{l}K \cdot 10^{-3}, \\
\mathbf{g} /\left(\mathbf{m}^{2} \mathbf{h}\right)\end{array}$ & $\begin{array}{l}Z, \\
\%\end{array}$ & $\begin{array}{l}K \cdot 10^{-3}, \\
\mathbf{g} /\left(\mathbf{m}^{2} \mathbf{h}\right)\end{array}$ & $\begin{array}{l}Z, \\
\%\end{array}$ \\
\hline \multirow{3}{*}{ M10G2k } & 0 & 73.0 & 40 & 21.0 & 30 & 13.5 & 55 \\
\hline & 5 & 65.1 & 47 & 21.0 & 29 & 9.0 & 70 \\
\hline & 10 & 70.0 & 43 & 21.3 & 29 & 10.5 & 65 \\
\hline \multirow{3}{*}{ WMO } & 0 & 59.0 & 52 & 19.8 & 34 & 12.6 & 58 \\
\hline & 5 & 90.9 & 26 & 19.8 & 34 & 9.0 & 70 \\
\hline & 10 & 86.0 & 30 & 19.5 & 35 & 7.0 & 75 \\
\hline
\end{tabular}

The protective efficacy of oil compositions with Cortec VCl-368D was investigated, in addition to steel, in relation to copper M2 and brass L62 in $0.5 \mathrm{M} \mathrm{NaCl}$ solution (Table 4). In the case of brass, the values of the protective effectiveness are higher than for copper and steel. For copper, the investigated compositions are generally not effective in a chloridecontaining medium, since the protective effect does not exceed $40 \%$.

The high protective efficiency of the investigated compositions with respect to steel, observed during tests in a thermal moisture chamber G-4, is confirmed by the results of twomonth tests in an open site (Table 5). The best protective effect is shown by the compositions based on the WMO and M10G2k oils.

Table 5. Results of two-month (September-October 2020) tests of St3 samples coated with the oil compositions in an open site.

\begin{tabular}{ccccccc}
\hline \multirow{2}{*}{$\begin{array}{c}\text { Cortec VpCI-368 D } \\
\text { concentration, wt } \%\end{array}$} & \multicolumn{2}{c}{$\mathbf{I - 2 0 A}$} & \multicolumn{2}{c}{ M10G2k } & \multicolumn{2}{c}{ WMO } \\
\cline { 2 - 7 } & $\boldsymbol{K}, \mathbf{g} /\left(\mathbf{m}^{2} \mathbf{h}\right)$ & $\boldsymbol{Z}, \boldsymbol{\%}$ & $\boldsymbol{K}, \mathbf{g} /\left(\mathbf{m}^{\mathbf{2}} \mathbf{h}\right)$ & $\boldsymbol{Z}, \boldsymbol{\%}$ & $\boldsymbol{K}, \mathbf{g} /\left(\mathbf{m}^{\mathbf{2}} \mathbf{h}\right)$ & $\boldsymbol{Z}, \boldsymbol{\%}$ \\
\hline 0 & 0.00325 & 35 & 0.00265 & 47 & 0.00250 & 50 \\
3 & 0.00075 & 85 & 0.00035 & 93 & 0.00040 & 92 \\
5 & 0.00065 & 87 & 0.00030 & 94 & 0.01260 & 93 \\
10 & 0.00055 & 89 & 0.00030 & 94 & 0.01260 & 93 \\
Control & 0.0050 & & & & & \\
\hline
\end{tabular}

Determination of the theoretical consumption of the oil compositions was carried out by gravimetrical method based on obtaining a single-layer coating of a given thickness without taking into account of irrecoverable losses (Table 6). For all the oil compositions (OC) at a concentration of 5-10 wt\% Cortec VCl-368D its consumption does not exceed $1 \mathrm{~g} / \mathrm{m}^{2}$. Moreover, a formation of the coating at an elevated temperature $\left(70^{\circ} \mathrm{C}\right)$ helps to reduce the consumption of the additive. 
Table 6. Theoretical consumption of Cortec VCl-368D for coating deposition at 20 and $70^{\circ} \mathrm{C}$.

\begin{tabular}{|c|c|c|c|c|c|c|c|}
\hline \multirow[b]{2}{*}{ Oil } & \multicolumn{2}{|c|}{ Concentration } & \multirow{2}{*}{$\begin{array}{c}\text { Temperature } \\
\text { of coating } \\
\text { deposition, }{ }^{\circ} \mathrm{C}\end{array}$} & \multirow{2}{*}{$\begin{array}{c}\mathrm{OC} \\
\text { density, } \\
\mathrm{kg} / \mathbf{m}^{3}\end{array}$} & \multirow{2}{*}{$\begin{array}{c}\text { Coating } \\
\text { thickness } \\
h, \mu \mathrm{m}\end{array}$} & \multicolumn{2}{|c|}{$\begin{array}{l}\text { Theoretical } \\
\text { consumption }\end{array}$} \\
\hline & $\begin{array}{c}\text { Oil, } \\
\text { wt \% }\end{array}$ & $\begin{array}{c}\text { Cortec VpCI- } \\
368 \text { D, wt } \%\end{array}$ & & & & $\begin{array}{c}\mathrm{OC} \\
\mathrm{kg} / \mathrm{m}^{2}\end{array}$ & $\begin{array}{c}\text { Cortec } \\
\text { VpCI-368 D, } \\
\text { g/m² }\end{array}$ \\
\hline \multirow{6}{*}{$\mathrm{I}-20 \mathrm{~A}$} & \multirow[t]{2}{*}{100} & \multirow{2}{*}{-} & 20 & \multirow{2}{*}{890} & 19.1 & 0.017 & 0 \\
\hline & & & 70 & & 5.1 & 0.004 & 0 \\
\hline & \multirow{2}{*}{95} & \multirow{2}{*}{5} & 20 & \multirow{2}{*}{878} & 20.2 & 0.018 & 0.9 \\
\hline & & & 70 & & 14.6 & 0.013 & 0.7 \\
\hline & \multirow{2}{*}{90} & \multirow{2}{*}{10} & 20 & \multirow{2}{*}{876} & 20.6 & 0.018 & 0.9 \\
\hline & & & 70 & & 16.3 & 0.014 & 0.7 \\
\hline \multirow{6}{*}{ M10G2k } & \multirow{2}{*}{100} & \multirow{2}{*}{-} & 20 & \multirow{2}{*}{884} & 19.5 & 0.017 & 0 \\
\hline & & & 70 & & 6.0 & 0.005 & 0 \\
\hline & \multirow{2}{*}{95} & \multirow{2}{*}{5} & 20 & \multirow{2}{*}{887} & 19.9 & 0.018 & 0.9 \\
\hline & & & 70 & & 10.6 & 0.010 & 0.5 \\
\hline & \multirow{2}{*}{90} & \multirow{2}{*}{10} & 20 & \multirow{2}{*}{893} & 21.0 & 0.019 & 1.0 \\
\hline & & & 70 & & 11.0 & 0.010 & 0.5 \\
\hline \multirow{6}{*}{ WMO } & \multirow{2}{*}{100} & \multirow{2}{*}{-} & 20 & \multirow{2}{*}{866} & 20.3 & 0.017 & 0 \\
\hline & & & 70 & & 8.5 & 0.007 & 0 \\
\hline & \multirow{2}{*}{95} & \multirow{2}{*}{5} & 20 & \multirow{2}{*}{869} & 23.5 & 0.015 & 0.8 \\
\hline & & & 70 & & 11.4 & 0.010 & 0.5 \\
\hline & \multirow{2}{*}{90} & \multirow{2}{*}{10} & 20 & 871 & 17.9 & 0.015 & 0.8 \\
\hline & & & 70 & & 12.8 & 0.010 & 0.5 \\
\hline
\end{tabular}

\section{Conclusion}

The protective performance of metal coatings based on the petroleum oils (I-20A, TKp, M10G2k and WMO) and Cortec VpCI-368D, a mixture of an organic solvent with a volatile inhibitor, has been investigated. The oil compositions with Cortec VpCI-368D are well wetted with water, they themselves spread over the steel surface, displacing water layers, and are characterized by low surface tension.

The protective efficiency of the composition of industrial oil I-20A and Cortec VpCI$368 \mathrm{D}(5-10 \%)$ at a short-term exposure of a coated steel electrode in a $0.5 \mathrm{M} \mathrm{NaCl}$ solution $(Z=97-98 \%)$ was estimated on the basis of polarization curves. 
Compositions of the petroleum oils with Cortec VpCI-368D (5-10 wt\%) show high protective efficiency in relation to carbon steel in a thermal moisture chamber and in natural conditions. These compositions are most effective in relation to L62 brass in a chloridecontaining neutral solution; it is impractical to use them to protect copper, since the protective effect does not exceed $40 \%$. In relation to carbon steel in these conditions, only compositions with commercial oil I-20A are advisable.

Consumption of Cortec VCl-368D for coating deposition at 20 and $70^{\circ} \mathrm{C}$ was calculated.

\section{Acknowledgements}

The experimental results were obtained using the equipment of the Center for Collective Use of Scientific Equipment of TSU named after G.R. Derzhavin.

\section{References}

1. E.N. Kablov, Strategic directions for the development of materials and technologies for their processing for the period up to 2030, Aviatsionnye materialy i tekhnologii (Aviation materials and technologies), 2012, 5, 7-17 (in Russian).

2. L.S. Kozlova, S.V. Sibilova, D.V. Chesnokov and A.E. Kutyrev, Corrosion inhibitors (review), Aviatsionnye materialy i tekhnologii (Aviation materials and technologies), 2015, 2, 67-75 (in Russian). doi: 10.18577/2071-9140-2015-0-2-67-75

3. V.I. Vigdorovich, N.V. Shel, L.E. Tsygankova and P.N. Bernatsky, Oil-based preservative materials for protection of copper against corrosion in atmospheres containing $\mathrm{SO}_{2}$, Int. J. Corros. Scale Inhib., 2015, 4, no. 3, 210-220. doi: 10.17675/2305-6894-2015-4-3-210-220

4. V.I. Vigdorovich, L.E. Tsygankova, N.V. Shel, L.G. Knyazeva, A.A. Uryadnikov and E.G. Kuznetsova, Kinetics and mechanism of electrode reactions in corrosion of some metals covered with oil films in acid and neutral chloride environments, Prot. Met. Phys. Chem. Surf., 2016, 52, 1157-1165. doi: 10.1134/S2070205116070170

5. V.I. Vigdorovich, L.E. Tsygankova, L.G. Knyazeva and N.V. Shel, Protective Effectiveness of Oil Compositions in the Presence of Sulfur-Containing Corrosion Stimulators, Chem. Technol. Fuels Oils, 2020, 56, no. 4, 570-579.doi: 10.1007/s10553$\underline{020-01169-9}$

6. Yu.I. Kuznetsov, N.N. Andreev, O.A. Goncharova and A.V. Agafonkin, On the protection of metals from corrosion when moisture condensation on them by volatile inhibitors, Korroz.: Mater., Zashch. (Corrosion: materials, protection), 2009, no. 10, 29-33 (in Russian). 
7. V.I. Vigdorovich, L.G. Knyazeva, M.V. Vigdorowitsch, L.E. Tsygankova, A.N. Dorokhova and N.V. Shel', Evaluation of the Protective Efficiency of IFKHAN114 Volatile Inhibitor Against Atmospheric Corrosion of Copper by Polarization Measurements, Polym. Sci., Ser. D, 2019, 12, 162-166. doi: $10.1134 / \mathrm{S} 1995421219020254$

8. E.E. Ebenso and M.A. Ouraishi, Volatile corrosion inhibitors for ferrous and nonferrous metals and alloys: A review, Int. J. Corros. Scale Inhib., 2018, 7, no. 2, 126150. doi: $10.17675 / 2305-6894-2018-7-2-2$

9. N.V. Danyakin and A.A. Curuga, Modern volatile inhibitors of atmospheric corrosion (review), Auditorium (Electronic scientific journal of Kursk State University), 2017, 13, no. 1, 1-7 (in Russian).

10. A.I. Petrashev, V.V. Klepikov, L.G. Knyazeva and I.V. Zarapina, Express-method for assessing the wetting properties of conservation compositions, Nauka $v$ tsentralnoi Rossii (Science in Central Russia), 2018, 4, no. 34, 73-85 (in Russian). 